\section{Manipulation of Flowering Time by Pruning of Protea cv. Sylvia (P. eximia $\mathrm{X} P$. susannae)}

\author{
Audrey I. Gerber ${ }^{1}$, Karen I. Theron ${ }^{2}$, and Gerard Jacobs ${ }^{3}$ \\ Department of Horticultural Science, University of Stellenbosch, Private Bag \\ X1, Matieland 7602, South Africa
}

Additional index words. floral initiation, ornamental plants, Proteaceae

\begin{abstract}
The date of pruning affected flowering time of Protea cv. Sylvia (P. eximia $\times$ P . susannae) by influencing the flush on which inflorescence initiation occurred, and the harvest could be manipulated to fall within the optimum marketing period for export to Europe. Flowers initiated on the spring flush reached anthesis in January-February, those on the first and second summer flushes in April-May and July-August, respectively, and those on the autumn flush in November-December. Thus, flowering shoots harvested within the optimum marketing period (September to February) initiated inflorescences on the autumn and spring flushes. Because shoots on the spring flush initiated inflorescences readily, many flowering shoots harvested in January and February (following initiation the previous spring) were short and therefore unmarketable. For commercial production, pruning in July is recommended to allow harvest in October-December of the following year. Since the vegetative and reproductive cycles necessary to produce inflorescences on long stems span more than a year, a biennial cropping system is recommended.
\end{abstract}

The commercial production of Proteaceae for cut flowers is increasing worldwide. Proteaceae grown in southern Africa are exported mainly to flower markets in Europe. The demand for proteas is high during the European winter (September to February) and this is considered as the optimum marketing period for export. To optimize expansion of the industry it is important both to ensure an even distribution of product availability during the optimum marketing period, and to target peaks of harvest for times of high market demand. This can be done by manipulating and extending the natural flowering times.

The flowering times of proteas cultivated in Southern African can be classified broadly into three categories. The first category contains the summer to autumn (January to May) flowering types. Flowers develop terminally on the spring flush. Development continues during spring and summer and flowers reach

Received for publication 16Feb. 2000. Accepted for publication 1 Nov. 2000. This paper is a portion of a $\mathrm{PhD}$ thesis submitted by A.I. Gerber to the Univ. of Stellenbosch. The work was done under the guidance of G. Jacobs and K.I. Theron and was completed for graduation in Mar. 2000. The thesis was evaluated and accepted by E. Rabe (Dept. of Horticultural Science, Univ. of Stellenbosch), P.J. Robbertse (Dept. of Plant Production and Soil Science, Univ. of Pretoria), and J. Ben-Jaacov (Dept. of Ornamental Horticulture, The Volcani Centre). The cost of publishing this paper was defrayed in part by the payment of page charges. Under postal regulations, this paper therefore must be hereby marked advertisement solely to indicate this fact.

${ }^{1}$ To whom reprint requests should be addressed. Current address: Ovens Research Station, P.O. Box 235, Myrtleford, VIC 3737, Australia. E-mail address: Audrey.Gerber@nre.vic.gov.au

${ }^{2}$ Associate Professor.

${ }^{3}$ Professor. anthesis during the period January to May (Gerber et al., 2001). Examples are Protea neriifolia $\mathrm{R}$. Br. selections and hybrids (e.g., 'Satin Pink', 'Kouga', and 'Carnival'), 'Pink Ice' (P. compacta R. Br. X P. susannae Phill.), and 'Ivy' (a P. lacticolor Salisb. hybrid). Proteas in the second category also initiate flowers on the spring flush, but visual development does not start until January (Gerber et al., 2001). Inflorescence development continues during late summer and winter, and anthesis occurs in late winter to early summer (July to October), depending on the time required for inflorescence development. Protea magnifica Link selections and hybrids (e.g., 'Susara', 'Lady Di', and 'Sheila') belong in this category. The third category includes those proteas that can initiate flowers at any time of year. Inflorescence development directly follows initiation and the time of anthesis depends on the time of initiation. Protea eximia (Salisb. ex Knight) Fourc. selections and hybrids (e.g., 'Sylvia' and 'Cardinal') can produce flowers throughout the year. These types have, in effect, an open window for inflorescence initiation whereas the former two categories have a limited window for inflorescence initiation.

The open window characteristic of $P$. eximia allows manipulation of plants to flower at a specific time of year. Flowering at any time during the year suggests that flowers can be initiated terminally on any of the four growth flushes produced during shoot elongation of 'Sylvia'. The most vigorous growth flush on 'Sylvia' plants occurs in spring after a period of winter dormancy. In summer one or two growth flushes occur, termed the first and second summer flushes, which are followed by a short, less vigorous autumn flush. No shoot growth occurs during winter (Malan and le Roux, 1995). The primary effect of pruning is to control and direct shoot growth. Pruning plants at different times of the year may be an effective method to indirectly manipulate time of flowering by controlling shoot growth. The objective of this study was to develop a technique that would enable growers to schedule the harvest of $P$. eximia to meet periods of high market demand.

\section{Materials and Methods}

Plants of Protea cv. Sylvia (P. eximia $\times$ P. susannae) were grown in a commercial plantation near Stellenbosch, Western Cape, South Africa (lat. $33^{\circ} 15^{\prime} \mathrm{S}$; long. $19^{\circ} 07^{\prime} \mathrm{E}$ ). Water needs were met exclusively by natural rainfall. The Stellenbosch climate is Mediterranean, with cool, wet winters (average maximum $17.6^{\circ} \mathrm{C}$ and minimum $8.1^{\circ} \mathrm{C}$ ) and hot, dry summers (average maximum $27.2^{\circ} \mathrm{C}$ and minimum $\left.14.8{ }^{\circ} \mathrm{C}\right)$. The area receives an annual rainfall of 600 to $700 \mathrm{~mm}$, with most of the rain falling in winter between April and August. Plants were grown at a spacing of $1 \mathrm{~m}$ within the row and $4 \mathrm{~m}$ between rows and were not fertilized. Pest and disease management practices necessary to produce export quality flowers were applied.

Rate of inflorescence development. Shoots with inflorescences on the spring, first and second summer, and autumn flushes were tagged when inflorescences were $\approx 10 \mathrm{~mm}$ in diameter. Ten inflorescences were measured for each type of growth flush. The basal diameter of the inflorescence was measured every 2 weeks until anthesis. Measurements commenced in Spring 1997 and continued until mid-Summer 1998.

Pruning experiments. Pruning entailed heading both flowering and nonflowering shoots, leaving a $15-\mathrm{cm}$ portion of the stem to serve as a bearer for subsequent growth. Spindly shoots were removed by thinning cuts. Pruning released lateral buds from apical dominance, resulting in growth of vegetative shoots in flushes, elongation of which stopped when inflorescence initiation occurred terminally. For 24 months following pruning, flowering shoots were harvested when the flowers were commercially mature, leaving a $15-\mathrm{cm}$ portion of stem to serve as a bearer, as is done in commercial practice. These flowering shoots were brought to the laboratory, where stem length was measured and date of harvest was recorded.

In Expt. 1, plants were pruned on seven dates at 4-week intervals from 23 Sept. 1993 to 10 Mar. 1994. The experimental design was a randomized complete block with seven singleplant replicates. A total of 49 plants were used.

Experiment 2 was started in Apr. 1996, and plants were pruned at 4-week intervals from 26 Apr. to 13 Sept. 1996. The same design, number of replicates, and method of pruning were used as in Expt. 1. In total, 42 plants were used.

Statistical analysis. Analysis of variance was performed using the SAS program (SAS Institute, 1990). Logit transformation of the data was performed on values expressed as 
Fig. 1. (right) Basal diameter of Protea cv. Sylvia inflorescences when subtended by different growth flushes, measured from $10 \mathrm{~mm}$ to anthesis. Standard deviations $(\mathrm{n}=10)$ for each data point are represented by vertical bars. Average monthly maximum (max.) and minimum (min.) temperatures $\left({ }^{\circ} \mathrm{C}\right)$ indicate seasonal changes (data courtesy of the South African Weather Bureau).

percentages. One plant died during Experiment 1 and, because of missing data, least significant difference (LSD) values were calculated using harmonic means.

\section{Results}

Rate of inflorescence development. Visual development of inflorescences subtended by the spring growth flush started on 22 Oct. 1997 and anthesis occurred on 28 Jan. 1998 (Fig. 1). Inflorescences subtended by the first summer flush developed from 14 Jan. to 26 Apr. 1998, by the second summer flush from 14 Apr. to 25 Aug. 1998, and by the autumn flush from 17 June to 13 Nov. 1998. A similar rate of development (over a period of 3 months) occurred for flowers borne on the spring, and on the first and second summer flushes, reaching anthesis in January, May, and August, respectively. Flowers borne on the autumn flush (which developed through winter) had a slower rate of development (Fig. 1), and anthesis occurred in mid-November.

Pruning experiments. The time of pruning influenced the pattern of distribution of time of flowering in both experiments (Fig. 2). When plants were pruned in Sept. or Oct. 1993, most inflorescences were harvested from Nov. 1994 to Jan. 1995 (Fig. 2 A and B). The main peak shifted to Jan. and Feb. 1995 when plants were pruned in Nov. 1993 (Fig. 2C), Dec. 1993 (Fig. 2D), or Jan. 1994 (Fig. 2E). When pruning was delayed until Feb. or Mar. 1994 (Fig. 2 F and G), only $\approx 25 \%$ of the harvest occurred in January, while the rest was spread more or less evenly over $10-11$ months. When plants were pruned in Apr. 1996 (Fig. $2 \mathrm{H})$, a harvest peak occurred during Oct. to Dec. 1997. The peak shifted to include Jan. 1998 when plants were pruned later, in May to Aug. 1997 (Fig. 2I-L), and the shift in harvest continued with later pruning, until the main peak of harvest occurred only in Dec. 1997 and Jan. 1998 following pruning in Sept. 1996 (Fig. 2M).

The time taken from pruning to harvest depended upon the time of pruning; the shortest time was 10 months, following pruning in Mar. 1994 (Fig. 2G). Flowers were initiated on the spring flush of the same year, and were harvested on short stems in Jan. 1995. In contrast, the harvest peak occurred 20 months after pruning in Apr. 1996, although the first few flowers were harvested 5 months earlier (Fig. 2H).

Despite differences in time and distribution of harvest, there were no differences in the total number of flowers harvested from plants pruned between Sept. 1993 and Mar. 1994 (Table 1 ), with an average of $33 \pm 4$ flowers per plant. In the second pruning experiment (pruning from Apr. 1996 to Sept. 1996), the time of

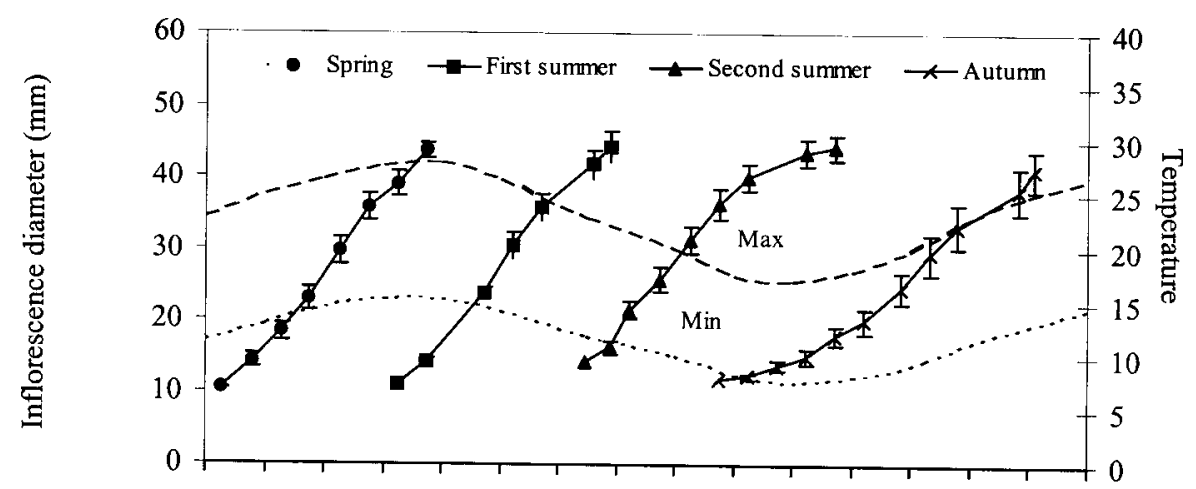

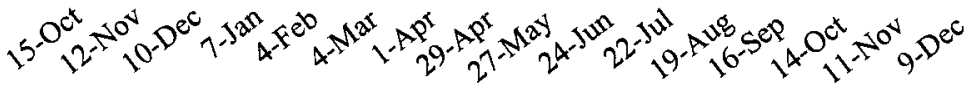

Date in 1993-94
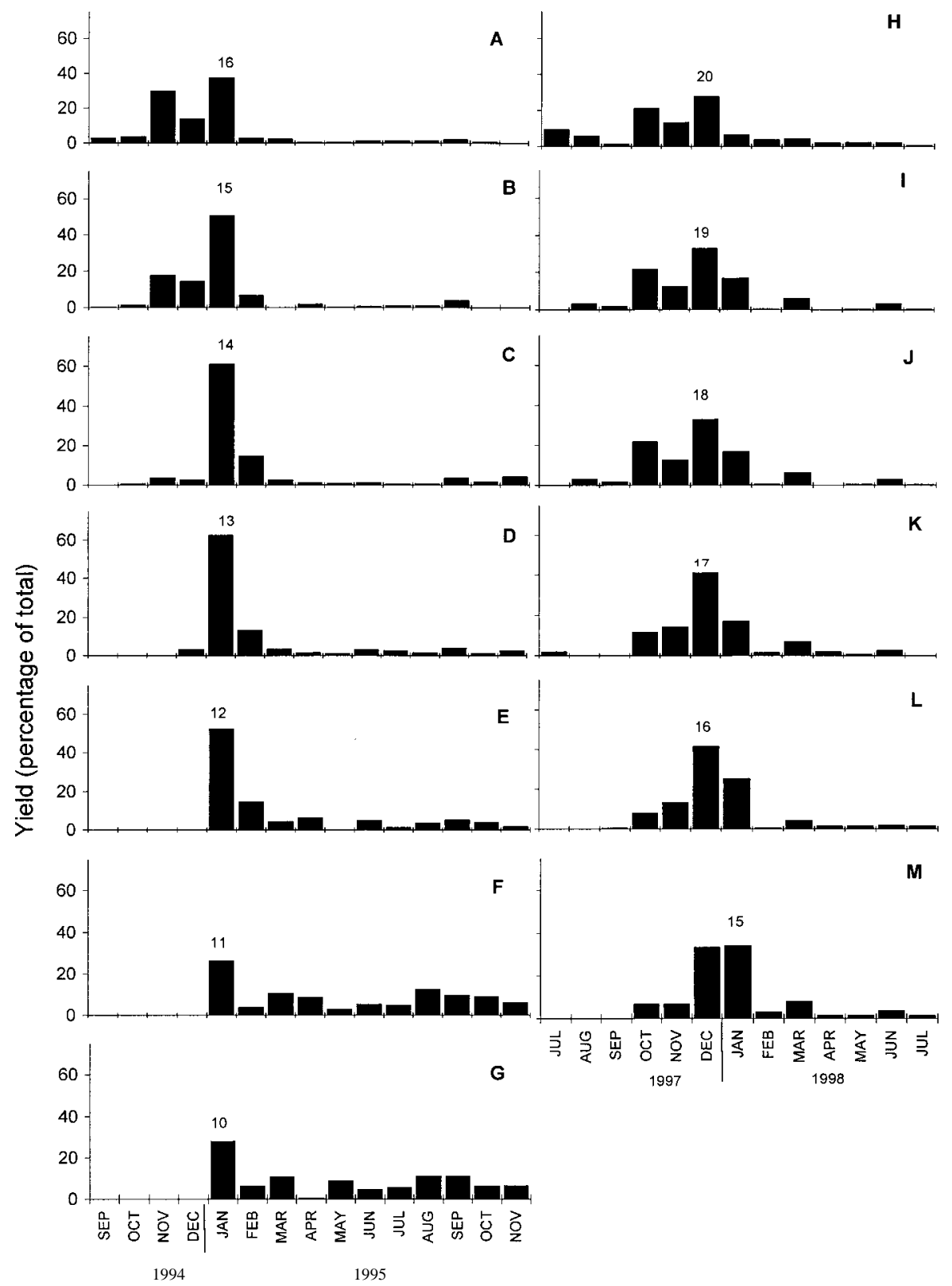

Fig. 2. Effect of date of pruning on distribution of yield from Protea cv. Sylvia plants, expressed as a percentage of total yield. (A-G) Pruned from Sept. 1993-Mar. 1994, yield recorded in 1994-95; (HM) pruned from Apr.-Sept. 1996, yield recorded in 1998-99. Numbers above columns indicate time from pruning to harvest in months. 
Table 1. Effect of pruning date on number of stems harvested from Protea cv. Sylvia plants. Yield is reported as the total number of stems harvested, as well as according to marketing criteria, i.e., number of stems $>40 \mathrm{~cm}$, number harvested within the optimum marketing period (September to February), and the number that fulfill both criteria.

\begin{tabular}{|c|c|c|c|c|c|c|c|}
\hline \multirow[b]{4}{*}{ Pruning date } & \multicolumn{7}{|c|}{ Stems harvested per plant } \\
\hline & \multirow[b]{3}{*}{ Total } & & & \multicolumn{4}{|c|}{ September to February } \\
\hline & & \multicolumn{2}{|c|}{$>40 \mathrm{~cm}$} & \multicolumn{2}{|c|}{ Total } & \multicolumn{2}{|c|}{$>40 \mathrm{~cm}$} \\
\hline & & No. & $\%^{2}$ & No. & $\%^{2}$ & No. & $\%^{z}$ \\
\hline \multicolumn{8}{|c|}{ Expt. 1. 1993-94 } \\
\hline 23 Sept. & $30 a^{y}$ & $24 \mathrm{ab}$ & 80 & $28 \mathrm{ab}$ & 93 & $23 \mathrm{a}$ & 77 \\
\hline 21 Oct. & $38 \mathrm{a}$ & $30 \mathrm{a}$ & 79 & $36 \mathrm{a}$ & 95 & $28 \mathrm{a}$ & 74 \\
\hline 18 Nov. & $35 \mathrm{a}$ & $24 \mathrm{ab}$ & 69 & $33 \mathrm{ab}$ & 94 & $22 \mathrm{a}$ & 63 \\
\hline 16 Dec. & $35 \mathrm{a}$ & $25 \mathrm{ab}$ & 71 & $31 \mathrm{ab}$ & 89 & $21 \mathrm{a}$ & 60 \\
\hline 13 Jan. & $31 \mathrm{a}$ & $15 \mathrm{c}$ & 48 & $25 \mathrm{bc}$ & 81 & $9 \mathrm{~b}$ & 29 \\
\hline 10 Feb. & $26 \mathrm{a}$ & $17 \mathrm{bc}$ & 65 & $16 \mathrm{c}$ & 62 & $8 \mathrm{~b}$ & 31 \\
\hline 10 Mar. & $34 \mathrm{a}$ & $16 \mathrm{bc}$ & 47 & $17 \mathrm{c}$ & 50 & $8 \mathrm{~b}$ & 24 \\
\hline \multicolumn{8}{|c|}{ Expt. 2. 1996} \\
\hline 26 Apr. & $30 \mathrm{ab}$ & $25 \mathrm{ab}$ & 84 & $23 \mathrm{ab}$ & 77 & $18 \mathrm{ab}$ & 61 \\
\hline 24 May & $23 \mathrm{bc}$ & $20 \mathrm{~b}$ & 84 & $20 \mathrm{~b}$ & 87 & $17 \mathrm{~b}$ & 73 \\
\hline 21 June & $33 \mathrm{a}$ & $30 \mathrm{a}$ & 92 & $29 \mathrm{a}$ & 89 & $27 \mathrm{a}$ & 82 \\
\hline 19 July & $21 \mathrm{bc}$ & $18 \mathrm{~b}$ & 90 & $18 \mathrm{~b}$ & 85 & $15 \mathrm{~b}$ & 75 \\
\hline 16 Aug. & $27 \mathrm{bc}$ & $24 \mathrm{ab}$ & 88 & $24 b$ & 88 & $21 \mathrm{ab}$ & 77 \\
\hline 13 Sept. & $19 \mathrm{c}$ & $19 \mathrm{~b}$ & 98 & $16 \mathrm{~b}$ & 79 & $16 \mathrm{~b}$ & 77 \\
\hline
\end{tabular}

${ }^{\text {zPercentage of total yield }}$

${ }^{y}$ Mean separation within columns and experiments by LSD, $P \geq 0.05 ; \mathrm{n}=7$.

pruning significantly affected yield (Table 1 ). The lowest yield was obtained from plants pruned in Sept. 1996.

Stem length and time of harvest affect marketing quality. Stems $\geq 40 \mathrm{~cm}$ long are considered to be of export quality, and the demand for proteas is highest in Europe, as are prices, from September to February. The marketable portion of the harvest is, therefore, the number of stems longer than $40 \mathrm{~cm}$ that are harvested between September and February (Table 1). Although $\approx 80 \%$ of the stems harvested from plants pruned in Sept. and Oct. 1993 had long stems, and $>90 \%$ of the total yield was harvested in the desired time period, only $77 \%$ and $74 \%$, respectively, fulfilled both requirements (Table 1). Delaying pruning until November or December reduced the marketable yield to $60 \%$ despite a high percentage being harvested in the relevant time period. Only $29 \%$ of the total yield harvested from plants pruned in Jan. 1994 was marketable, primarily due to short stems, since $81 \%$ were harvested from September to February. The low percentage of marketable stems from plants pruned in Feb. and Mar. 1994 was due to both short stems and unsuitable flowering time.

Pruning on all dates in 1996, except April, resulted in a marketable yield $>70 \%$ of the total yield (Table 1). The highest marketable yield $(82 \%)$ was attained when plants were pruned in June 1996. Only $61 \%$ of the yield from plants pruned in Apr. 1996 had ideal marketing characteristics, primarily due to unsuitable flowering time.

\section{Discussion}

The time of harvest of 'Sylvia' flowers is dependent on the flush on which inflorescence initiation occurs. Inflorescence development during spring and summer occurred at a similar rate. Inflorescences subtended by the autumn flush developed at a slower rate, prob- ably because of cooler weather in winter (Fig. 1). Anthesis occurred on the spring flush in January-February, on the first summer flush predominantly in April-May, on the second summer flush in July-August, and on the autumn flush in November-December. The inflorescences harvested in the ideal marketing period from September to February, therefore, were borne on the autumn and spring flushes.

Despite the fact that 'Sylvia' can flower at any time during the year, and can initiate inflorescences on any flush, it flowers more readily on the spring flush if subtended by one or more previous flushes. The peak of harvest occurring in Jan. 1995 following pruning in Sept. 1993 to Mar. 1994 is evidence of enhanced inflorescence initiation on the spring flush of 1994. Pruning on these dates resulted in production of at least one flush before winter. The presence of mature, overwintering leaves is essential for inflorescence initiation in Protea cvs. Carnival and Lady Di, which flower on the spring flush, only when it is subtended by one or more previous flushes (Gerber et al., 2001). Flower initiation predominantly on the spring flush of an overwintering shoot in 'Sylvia' is perhaps the expression of a facultative response to inductive conditions for which 'Carnival' and 'Lady Di' have an obligate requirement. The strong "signal" for initiation on the spring flush, together with strong synchrony of spring shoot growth, resulted in a sharp peak of harvest of flowers that were initiated on the spring flush.

Initiation on the autumn flush, although less prevalent than on the spring flush, occurred more frequently than did initiation on either summer flush. When plants were pruned in Apr. 1996, a flush was not produced before winter (data not presented), probably because of cooler temperatures, and no shoots initiated flowers on the same year's spring flush. Shoot growth resumed in spring, and the majority of flowers were initiated on the autumn flush of the following year. Flowers were harvested from Oct. to Dec. 1997.

According to De Swardt (1989) and Sedgley and Fuss (1992), working on Protea and Banksia, respectively, a shoot must attain a critical minimum length or diameter before inflorescence initiation can occur. Following pruning, 'Sylvia' shoots elongate by successive growth flushes until they have developed the necessary characteristics, at which time initiation will occur. If this pattern was rigidly adhered to by the plant, all shoots would be of similar length and the harvest would be uniformly distributed over time following pruning at different times. The strong "signal" for initiation on the spring flush reduced the time from pruning to harvest and resulted in inflorescence initiation occurring on short shoots when plants were pruned in January to March. Shoot growth began with the production of an autumn flush before winter commenced (data not presented), and initiation occurred on the spring flush of the same year. Plants pruned in Apr. 1996 failed to grow before winter, and did not produce an autumn flush, as did plants pruned in Mar. 1996 (data not shown). The first flush occurred in spring and no flowers were initiated on this spring flush. Vegetative growth continued before flower initiation occurred, hence a longer time elapsed from pruning to flowering.

In general, when plants were pruned in spring and early summer (August to October) a high percentage of the total yield had long stems and was picked during the period of high market demand from September and February. Plants pruned in midsummer (December and January) also produced most of the yield during the high demand period, but a very low percentage of these flowers had stems longer than $40 \mathrm{~cm}$. Plants pruned in late summer (February and March) produced short-stemmed flowers in January and February and longstemmed flowers later in the year, from September to November. Plants pruned in winter (May to July) produced a high percentage of marketable stems, but the yield appeared to fluctuate in response to climatic conditions. Inclement weather conditions following pruning could result in poor budbreak, leading to a lower yield. The high yield from plants pruned in June indicates that pruning in winter per se does not result in low yields. The reason for the lower yield following pruning in Sept. 1996 than in Sept. 1993 is not known.

Since the vegetative and reproductive cycles necessary to produce a long flowering stem span more than 1 year (12-17 months), annual cropping is not possible. Under South African conditions the best yield will be obtained when 'Sylvia' plants are pruned in June or July. Shoot growth will start in the spring of the same year and continue until autumn of the following year, when inflorescence initiation occurs. Flowers will have long stems and be ready for harvest during the peak marketing time of October to December. For commercial production, a system similar to that described for 'Carnival' (Gerber et al., 1995; Hettasch et al., 1997), with two blocks out of phase with one another, is recommended. 


\section{Literature Cited}

De Swardt, D.C. 1989. Aspects of the vegetative and reproductive development of selected Proteaceae cultivars. MSc Agr. Thesis, Univ. of Stellenbosch.

Gerber, A.I., E.J. Greenfield, K.I. Theron, and G. Jacobs. 1995. Pruning of Protea cv. Carnival to optimise economic biomass production. Acta
Hort. 387:99-106

Gerber, A.I., K.I. Theron, and G. Jacobs. 2001. Synchrony of inflorescence initiation and shoot growth in selected Protea cultivars. J. Amer. Soc. Hort. Sci. 126:182-187.

Hettasch, H.B., A.I. Gerber, K.I. Theron, and G. Jacobs. 1997. Pruning Protea cv. Carnival for biennial crops of improved yield and quality. Acta Hort. 453:127-133.
Malan, D.G. and R.D. Le Roux. 1995. Preliminary investigation into the effect of time of pruning on shoot growth and flowering time of Protea. Acta Hort. 387:91-97

SAS Institute. 1990. SAS/STAT user's guide, ver. 6. 4th ed., Vol. 1 and 2. SAS Inst., Cary, N.C.

Sedgley, M. and A. Fuss. 1992. Correct pruning lifts Banksia yields. Austral. Hort. 90(7):50-53. 